\title{
Quixote nas aulas de língua espanhola - leituras invertidas: um relato de experiência.
}

\section{Quixote in Spanish language classes - inverted readings: experiences report .}

Ana Raquel de Sousa Lima ${ }^{1}$

\begin{abstract}
Resumo
Compreende-se que as recepções dos clássicos como possibilidade de aquisição de riquezas, as quais já mencionava Ítalo Calvino, podem ser percebidas através das diversas leituras e releituras realizadas em obras literárias. Com isso, vê-se a necessidade de recepcioná-las em sala de aula. Partindo dessa ponderação, esse trabalho tem por objetivo refletir sobre a recepção do clássico de Cervantes, Dom Quixote de la Mancha, pelos alunos do segundo ano do ensino técnico integrado ao médio do IFPI, uma vez que a obra ainda se apresenta como um texto literário desconhecido para uma parcela desse público. Para subsidiar esse trabalho, são utilizadas as reflexões de Lajolo (2001), Candido (2004) e Cosson (2012). Portanto, identificou-se que, embora a obra cervantina seja um clássico da literatura espanhola, ela ainda merece uma atenção especial nas aulas de espanhol do ensino médio. Para além disso, observou-se a necessidade de uma formação por parte do professor de língua espanhola para realizar estas atividades em sala de aula de maneira significativa e prazerosa.
\end{abstract}

Palavras-chave: Literatura Espanhola. Dom Quixote. Aula de Espanhol.

\begin{abstract}
The receptions of the classics are understood as a possibility of acquiring richness, as Italo Calvino already mentioned, which can be acquired through the various readings and re-readings of literary works. Thus, we see the need to welcome them in the classroom. Based on this consideration, this work aims to reflect on the reception of the classic of Cervantes, The Ingenious Gentleman Don Quixote de la Mancha, by the sophomore students of technical education integrated to high school of the IFPI, since that novel is still presented as a literary text unknown to a portion of that audience. To support this work, we used the reflections of Lajolo (2001), Candido (2004) and Cosson (2012). Therefore, it was identified that, although the Cervantine work is a classic of Spanish literature, it still deserves special attention in high school Spanish classes. In addition, there was a need for training by the Spanish language teacher to accomplish these activities in the classroom in a meaningful and enjoyable way.
\end{abstract}

Keywords: Spanish Literature. Don Quixote. Spanish Classes.

\section{Considerações Iniciais}

Compreende-se a obra literária como "um objeto social muito específico. Para que ela exista, é preciso, em primeiro lugar, que alguém a escreva e que outro alguém leia", como afirma Lajolo (2001, p. 17); e que, "ler é bem mais do que seguir uma linha de letras e palavras", como bem pontua Cosson (2019, p.37). A partir desses pressupostos é necessário refletir sobre as leituras nas aulas de língua espanhola do ensino médio. Embora se perceba uma grande preocupação dos docentes em apresentar

\footnotetext{
${ }^{1}$ Mestre em Letras - Literatura. Instituto Federal do Piauí (IFPI) - Campus Teresina Central, Teresina, Piauí - Brasil. Orcid: https:// Orcid: 0000-0003-1417-1962.org/ E-mail: anaraquel@ifipi.edu.br
}

LínguaTec, Instituto Federal de Educação, Ciência e Tecnologia do Rio Grande do Sul, Bento Gonçalves 
diversos textos para fins de exames educacionais, os da literatura espanhola, que também fazem parte da esfera sociocultural, ainda não são inseridos de forma significativa nas recepções dos discentes em sala de aula.

Observa-se que nas duas menções acima há um ponto em comum, que é o ato de ler, isto é, o objeto social considerado específico por Lajolo (2001) necessita de alguém para lhe dar sentido por meio das diversas leituras realizadas. De acordo com Zilberman (2009, p. 18), "a leitura acontece quando a imaginação é convocada a trabalhar junto com o intelecto, responsável pelas operações de decodificação e entendimento de um texto ficcional". Segundo a pesquisadora, o resultado passa a ser a fruição da obra, sentimento que traz à tona o prazer evocado pelo estímulo dado ao imaginário do leitor. Sobre a imaginação, observa-se que, conforme Zilberman, muitas vezes ela é considerada um alheamento do universo imediato experimentado e conhecido do ser humano.

Essas diversas percepções sobre 0 ato de ler trazem à tona reflexões acerca das possibilidades de trabalhar com a literatura na escola, observando tanto a questão da motivação, da imaginação, como a questão da significação da obra sobre a perspectiva do letramento literário pontuado por Zilberman (2009), como a intelectualidade necessária na leitura, pois a significação leitora proporciona uma ampliação no horizonte de expectativa dos estudantes, que se faz a partir da motivação da imaginação do leitor. Com isso, o imaginário consegue navegar em outras águas diversas das que o leitor está habituado, como afirma Zilberman (2009).

A partir dessas reflexões, é importante pontuar a motivação para a realização da atividade que será demonstrada na continuação deste trabalho. Ela surgiu a partir de uma aula expositiva sobre a obra clássica da literatura espanhola - Dom Quixote de la Mancha - na qual, foi possível perceber um desconhecimento dos alunos com relação a esse texto literário. Este fato chamou a atenção por ser uma narrativa que permeia o repertório cultural desde a literatura infantil, em especial no Brasil, pelo olhar de Monteiro Lobato. Sobre os clássicos, tem-se que,

dizem-se clássicos aqueles livros que constituem uma riqueza para quem os tenha lido e
amado; mas constituem uma riqueza não menor para quem se reserva a sorte de lê-los pela
primeira vez nas melhores condições para apreciá-los (CALVINO, 1993, p. 10).

Com isso, imagina-se que as condições para as leituras literárias podem/devem surgir no ambiente escolar e no momento da aula. Então esse foi o ponto de partida da leitura do clássico cervantino de forma compartilhada pelos estudantes. Por conta dessas percepções, a aula acima mencionada tomou uma outra direção, vista como necessária para aproximar aqueles estudantes das 
riquezas que o clássico espanhol traz, tanto para a imaginação e criação leitora como para 0 desenvolvimento do capital cultural e intelectual dos estudantes.

Então é importante trazer à tona a perspectiva de Soares e Martins (2001), uma vez que eles perceberam o texto de Cervantes como objeto e lugar híbrido, a partir de releitura de Quixote na arte, especialmente a do artista plástico, Lupe de Souza Barbosa, que trabalha à luz da reciclagem. $O$ que chamou atenção na pesquisa desses autores foi a forma como 0 artista se aproximou da obra de Cervantes, segundo eles por meio midiático, assistindo ao programa, O Sítio do Pica-pau Amarelo.

Por meio dessas percepções dos pesquisadores, identificam-se outras possibilidades de promover a leitura do texto literário espanhol, ou seja, através de diversas representações artísticas. Com isso, tem-se a oportunidade de realizar as leituras diferentemente das que são feitas tradicionalmente na escola, as quais, dependendo do modo como são executadas, podem impossibilitar até mesmo a imaginação do leitor. Assim, verificam-se perspectivas distintas, porém com probabilidades significativas para motivar as recepções dos prováveis leitores de Quixote.

Nesse contexto, este relato de experiência tem como objetivo refletir a respeito das percepções estéticas, dos alunos de segundo ano do Ensino Médio do IFPI- Instituto Federal do Piauí, a partir da leitura do texto de Cervantes, uma vez que para Jauss, citado por Bonnici e Zollin ( 2005, p.156), "a qualidade e a categoria estética de um texto vêm dos critérios de recepção, do efeito produzido pela obra e de sua fama junto à posteridade". Para além disso, é importante mencionar que o alicerce das atividades propostas para esse trabalho foi um fragmento literário da obra Dom Quixote de la Mancha, apresentada no livro didático intitulado - Cercanía Joven (2016). Mesmo tendo consciência, como professora, de que o excerto não é suficiente para as recepções literárias, ele serviu como um fio condutor para a motivação à leitura do clássico.

Nesse cenário, entende-se que ler é ter uma compreensão de mundo, a partir de uma percepção individual, e que a prática da leitura literária e as potencialidades críticas surgirão ao longo do hábito leitor, como também a imaginação e a criatividade. Sobre essa reflexão, Cosson (2012, p. 40) expressa que "aprender a ler e ser leitor são práticas sociais que medeiam e transformam as relações humanas".

Diante do exposto, é relevante mencionar que as recepções leitoras aqui analisadas estão compreendidas entre os estudantes dos seguintes cursos: Eletrônica, Eletrotécnica, Contabilidade, Segurança do Trabalho e Mecânica, os quais se apresentam em faixa etária de 16 e 17 anos, salvo alguns que passaram por processos reprovativos. A quantidade de alunos por sala é de 35 a 45 discentes. Por ser um número elevado, preferiu-se estabelecer uma média de 5 alunos por sala, 
correspondendo a um estudante por equipe, para participarem da etapa do questionário avaliativo que foi aplicado após as atividades de leituras propostas para eles e realizadas em grupos.

A metodologia da pesquisa se desenvolveu tanto pelo método observacional ao longo das práticas leitoras, como pela abordagem técnica, por meio do instrumento questionário que foi aplicado com os alunos de cada sala, como foi mencionado acima. Sobre o recurso instrumental, é importante ressaltar, foi elaborado com perguntas mistas, a fim de que os discentes pudessem expressar suas percepções.

A partir do exposto, nota-se que a obra cervantina, assim como as atividades práticas, tiveram boa aceitação pelos alunos, de maneira que, em alguns casos, observou-se um despertar para a leitura da narrativa de Cervantes, fato identificado no momento em que alguns alunos mostraram o desejo de ir além dos conhecimentos adquiridos em sala de aula, buscando a obra na biblioteca , ou mesmo, a compra do livro para outras leituras. Esse fato é relevante, uma vez que o trabalho foi desenvolvido, não apenas para o conhecimento do fragmento do texto apresentado no livro didático, mas principalmente como uma motivação para a leitura da obra e o conhecimento das representações dela em outras artes.

\section{Reflexões sobre o texto literário nas aulas de Língua Espanhola}

A importância do ato de ler é compreendida por muitos como uma forma de emancipação dos pensamentos superficiais do senso comum para atingir uma outra compreensão significativa diante do campo social do qual o leitor faz parte ou não, como também reconhecer-se e passar a compreender as experiências do outro. Entretanto, sabe-se que desenvolver estas ações no ambiente escolar ainda não é algo fácil, especialmente quando se observam os muitos empecilhos internos e externos que contribuem para um distanciamento entre os textos e seus leitores.

Voltando-se essa percepção para uma escola que tem como mote um ensino técnico integrado ao médio, tais concepções tornam-se ainda mais específicas, pois geralmente o jovem que adentra a esse ambiente educacional passa a vislumbrar e ter como maior referencial cognitivo diversas leituras técnicas. Tal perspectiva, coaduna-se com as considerações realizadas por Fontana (2020), quando observou este mesmo fato em sua turma de segundo ano do ensino médio de Agropecuária no Campus Sertão do Instituto Federal de Educação, Ciência e Tecnologia no Rio Grande do Sul. De acordo com a pesquisadora no Campus, 
há muitos exemplares de obras relacionadas à área técnica, priorizadas pelo fato de que 0 foco da instituição é a formação técnica dos alunos. Além disso, o grupo de alunos envolvidos demonstrou clara resistência à leitura literária, priorizando leituras técnicas exigidas pelos professores. (FONTANA, 2020, p. 3).

Fato que demonstra uma possível semelhança nas instituições que ainda vivem sob uma ótica tecnicista e desvinculada da importância de se desenvolverem diversos olhares críticos e reflexivos a partir das leituras literárias. Pois, se por um lado o conhecimento específico é importante, por outro 0 literário é humanizador e consequentemente detém uma grande relevância também. Nesse contexto, Petit (2008), citado por Fontana (2020) traz à luz a contribuição de que "a leitura proporciona uma aproximação da democratização". Para Petit (2008), de acordo com Fontana (2020), "a ação de ler pode contribuir em diversos aspectos: "acesso ao conhecimento, apropriação da língua, construção de si mesmo, extensão do horizonte de referência, desenvolvimento de novas formas de sociabilidade".

Sob esses olhares acima referenciados e sobre a leitura literária nas aulas de língua espanhola nos cursos de segundo ano técnico, é que essa pesquisa se debruça, visto que pensar o ensino da língua espanhola, principalmente, para alunos do ensino médio, é conceber que geralmente a aula está baseada nas estruturas linguísticas da língua, enfatizando fonemas, vocabulário e textos, visando ao exame final da educação básica. Diante disso, nota-se que a leitura literária fica restrita a textos presentes no livro didático, muitas vezes fragmentados, fato que pressupõe uma leitura superficial das obras literárias pelos alunos.

Essas pontuações são reforçadas pelo olhar de Albaladejo (2007), que apresenta de forma restrospectiva a presença e o uso dos textos literários por diferentes enfoques metodológicos ao longo do século $X X$, sendo que nos anos 70 ,

\begin{abstract}
el foco de atención de los métodos de enseñanza varió, siendo los criterios lingüísticos los definitorios de los contenidos en la enseñanza de idiomas. Este nuevo enfoque, denominado estructural, pretendía romper con el modelo existente, y es por ello que la lengua literaria quedó suprimida de los programas de lengua, pasando a ser las estructuras lingüísticas y el vocabulario el foco de atención de las programaciones de lenguas extranjeras. (ALBALADEJO, 2007, p. 3)
\end{abstract}

Essa metodologia aparentemente não tem sofrido muitas mudanças no século XXI. Para além disso, verifica-se que a leitura literária na sala de aula passa a ser concebida como algo lateral, uma vez que são textos vistos por muitos professores como de difícil compreensão, ou mesmo, que necessitam de um tempo maior para serem bem aplicados ao ambiente escolar, o que não deixa de ser uma verdade até certo ponto, que deve ser analisada por ângulos diferentes, posto que o ensino da língua estrangeira perpassa por outros referenciais, tais como o cultural, que consiste em informações 
necessárias para o desenvolvimento do sujeito como cidadão. E, para que isso aconteça, é necessária uma aproximação a diversos mundos por meio de recepções ficcionais que o transporte a diferentes percepções sobre circunstâncias e/ou acontecimentos por vezes aceitos ou rechaçados.

Quanto à ampliação do horizonte de expectativa, vislumbra-se pela teoria da recepção, uma importante discussão através da ótica de Jauss no que concerne à perspectiva do leitor e do texto, fato abordado por Araújo e Silva (2015, p. 114), no artigo intitulado, A Estética da Recepção e sua Aplicabilidade pelo Método Recepcional: uma apresentação de Machado de Assis. Nele as pesquisadoras trazem à luz que,

a Estética da Recepção, desenvolvida por Hans Robert Jauss (1994), focaliza a experiência de leitura e propõe como primeira premissa o fato dos dois - leitor e obra -, estarem inseridos em horizontes históricos, sociais e culturais. Assim, elabora a teoria do Horizonte de Expectativas, combinações estético-ideológicas que viabilizam a criação e a recepção de um texto. (SILVA, ARAUJO, 2015, p. 114).

Complementando o pensamento de Jauss, elas argumentam que é no momento da recepção da obra que esses horizontes se entrecruzam, o do leitor e o do autor uma vez que, "a obra literária é ponto de encontro das duas visões de mundo, que podem se identificar ou repelir-se" (SILVA; ARAÚJO, 2015, p. 114). Por conta disso, é relevante pontuar as observações das pesquisadores no sentido de que 0 ato de recepção depende do grau de aproximação que se estabelece entre a obra literária e 0 leitor, tendo em vista aspectos sociais, culturais e ideológicos de ambos, os quais perpassam tanto pela recepção como pela significação do texto lido pelo leitor.

É importante coadunar a esses olhares uma investigação realizada por Silva e Pereira (2017), intitulada: A Inserção do Texto Literário em Aula de E/LE, porque nela as pesquisadoras têm por objetivo compreender como se dá, de forma aplicável, essa imersão literária. Ao longo do estudo, Silva e Pereira apresentam dados que foram observados a partir da análise de um questionário aos professores de uma escola sobre o ensino da literatura e sua aplicabilidade. Dentre as diversas percepções, merece destaque a de que o trabalho com o texto literário não é uma tarefa fácil, pois a escolha do texto a ser trabalhado não pode ser feita aleatoriamente e deve ser planejado vislumbrando o público leitor em diversos aspectos. As pesquisadoras enfatizam ainda que, apesar do texto literário ser uma relevante ferramenta que aprimora ainda mais as aulas de língua, muitos professores rechaçam esse recurso e se apoiam na afirmativa de que eles trazem complexidade linguística. Logo, neste último fato enunciado tem-se reforçadas as complexidades do trabalhar com literatura em sala de aula, como já foi pontuado acima. 
Nesse contexto, é relevante dialogar com García (2007), citado por Silva e Pereira (2017), quanto às cinco razões para incluir o texto literário no ensino e aprendizagem de línguas. Dentre elas está o caráter universal, vinculado às temáticas como: amor e morte; autenticidade, o valor cultural da literatura; riqueza linguística e compromisso pessoal do estudante com a obra que lê. Sobre essas razões, salta aos olhos a questão das diversas temáticas que podem ser compreendidas, refletidas e criticadas nas leituras significativas das obras literárias, fazendo o leitor, por meio da experiência leitora, perceber as diversas questões humanas, como também a riqueza linguística existente no tecido narrativo. Isso traz à tona a importância de o saber desenvolver-se também pelo contato com a literatura substancialmente quando se trabalha com língua estrangeira com o jovem do ensino médio.

Diante disso, é relevante que o olhar do professor de língua espanhola se volte também para a questão do letramento literário em sala de aula, pois, acredita-se que através dele o aluno conseguirá ampliar seus horizontes de expectativas de forma mais significativa. Conforme Cosson,

falta a uns e a outros uma maneira de ensinar que, rompendo o círculo da reprodução ou da permissividade, permita que a leitura literária seja exercida sem o abandono do prazer, mas com o compromisso de conhecimento que todo saber exige. (COSSON, 2012, p.23).

Diante desta argumentação de Cosson (2012), de que falta a uns e a outros uma maneira de ensinar e da percepção de Fontana (2020), quando desenvolveu ação da leitura literária, mesmo tendo que superar as resistências dos alunos para a realização da atividade, somando-se a isso, a verificação da necessidade de aproximar esses textos literários também pelas riquezas temáticas que apoiam as possíveis mudanças na perspectiva humanizadora nos estudantes é que se identifica a importância da leitura literária nas escolas indistintamente do foco ao qual ela está delineada. Contudo, é válido mencionar que, para trabalhar com esses textos, são necessários uma formação e um comprometimento do professor e apoio da escola para que a leitura seja prazerosa e significativa para o aluno, corroborando-se assim, as afirmações de Cosson no excerto acima.

Nesse contexto, vê-se que proporcionar uma leitura literária de maneira significativa, perpassa muitas questões que podem ser solucionadas por meio de atividades como as que foram referenciadas aqui por buscarem compartilhar experiências ficcionais com e entre os alunos, de maneira a proporcionar um rompimento de algumas construções e percepções de mundo, isto é, possibilitar um perceber-se e perceber o outro para além do real imposto convencionalmente na sociedade. Um outro ponto é a questão do horizonte de expectativa do professor, pois essas aulas exigem um conhecimento sobre textos literários, competências e habilidades para desenvolver e motivar 0 ato de leitura em sala 
de aula. Quanto a isso, Cosson (2012, p. 32) elenca alguns pontos sobre o momento da seleção dos textos literários e entre eles, destaca-se "o cabedal de leituras do professor. 0 professor é 0 intermediário entre o livro e o aluno, seu leitor final". Para o pesquisador:

os livros que ele lê ou leu são os que terminam invariavelmente nas mãos dos alunos. Isso explica, por exemplo, a permanência de certos livros no repertório escolar por décadas. É que tendo lindo naquela série ou naquela idade aquele livro, o professor tende a indicá-lo para seus alunos e assim, sucessivamente, do professor para o aluno que se fez professor. (COSSON, 2012, p. 32).

Todas estas reflexões acima referenciadas deixam claro que proporcionar a leitura literária na escola é uma atividade que se faz por meio de muitas mãos e que todas têm sua relevância no processo, dado que a construção do conhecimento está interrelacionada à questão da disponibilidade e do desejo de todos os envolvidos no processo educativo. Sabe-se que esse sentimento pode ser motivado no aluno pelos mediadores da leitura. Assim, o brio do texto, como pontua Barthes:

seria a sua vontade de fruição: lá onde precisamente ele excede a procura, [...] e através do qual tenta transbordar, forçar o embargo dos adjetivos - que são essas portas da linguagem por onde o ideológico e o imaginário penetram em grandes ondas. (BARTHES, 1987, p. 21).

Por fim, deve-se compreender que trabalhar o texto literário em sala de aula é uma atividade prazerosa, mas para que ela seja significativa requer diversas estratégias, escolhas e formações, visto que o refletir sobre o mundo diante de obras clássicas ou contemporâneas exige letramentos direcionados às narrativas propostas. Como já foi mencionado, as obras literárias trazem com elas diversas temáticas que perpassam diferentes momentos históricos que revelam experiências distintas e algumas semelhantes vivenciadas pelos personagens ao longo do enredo e são elas que proporcionarão ao leitor suas mudanças de perspectivas referenciais.

\section{Metodologia}

A metodologia deste trabalho consiste no método recepcional que, segundo Souza (2013), "algumas vezes também é chamado de processo de recepção textual,

que constitui um todo único e integrado; porém, por questões didáticas de facilidade de entendimento e de aplicação efetiva, pode ser dividido em diferentes etapas, que são subsequentes e estão interligadas entre si. Esses passos se referem ao horizonte de expectativas do aluno e dizem respeito à sua determinação, ao seu atendimento, à sua ruptura, ao seu questionamento e, finalmente, à sua ampliação". (SOUZA, 2013, p. 131) 
E quanto às referenciadas, pode-se compreendê-las como: determinação do horizonte de expectativas, rompimento com o horizonte de expectativas, questionamento sobre o horizonte de expectativas e ampliação do horizonte de expectativas. Tais procedimentos didáticos para aplicação do método devem ser compreendidos não como fórmula mágica de ensinar literatura, conforme pontua Souza (2013), devem ser vistos mais como norteadores para aplicação de atividades com textos literários.

Para além dessas etapas, é necessário contemplar também a estratégia da sequência básica pontuada por Cosson (2014), como forma de inter-relacionar as duas metodologias no intuito de mobilizar a recepção dos leitores de Quixote na sala de aula. Sobre as estratégias, partiu-se do primeiro passo proposto, que é a motivação, isto é, preparação do aluno para entrar no texto, em seguida utilizaram-se as etapas, introdução, leitura e interpretação. 0 desenvolvimento será demonstrado na fase de análise desta investigação.

Este trabalho teve uma duração mensal e, para cada semana (aula), foram escolhidas temáticas diferenciadas voltadas para a motivação da leitura do clássico espanhol - Dom Quixote de la Mancha. De maneira que as ações se iniciaram a partir de uma atividade proposta pelo livro didático de espanhol. A princípio, sugeriu-se à turma a leitura do fragmento da obra trazida pelo livro, como uma forma de motivação na perspectiva da sequência básica de Cosson (2014) e no caso do método recepcional, denominada de determinação do horizonte de expectativas.

Alinhadas as duas estratégias leitoras, a execução da atividade motivou um momento de discussão em sala de aula, sobre a compreensão do fragmento, trazendo à tona o olhar sobre personagens, ação e espaço vislumbrado por eles no momento da leitura. É importante mencionar que o fragmento trazia a clássica cena da aventura dos moinhos de vento.

Em sequência, os alunos foram divididos em equipes para pesquisarem sobre a obra e outras áreas do conhecimento que trazem ressignificações dela. As áreas propostas foram: dramaturgia, dança, música, arquitetura e adaptações do clássico para o público infanto-juvenil. As temáticas sugeridas nessa etapa foram: Quixote - perspectiva histórica, autor e obra; Quixote nas artes e um olhar científico sobre Quixote (estudos realizados sobre a obra). Esse segundo momento pode ser contemplado como o atendimento ao horizonte de expectativa, que na sequência básica, pode ser compreendido como introdução; entretanto, neste trabalho, a introdução ao mundo de Quixote se dá, não pela leitura da obra diretamente, mas pelas leituras invertidas proporcionadas por outras formas sensíveis da arte e da ciência compreendendo com isso a inversão da prática leitora. Ou seja, os alunos 
reconheceram a significância do protagonista cervantino e suas aventuras narradas no texto literário por meio de pesquisas em outras artes para então, apreciá-lo na leitura da obra impressa ou digitalizada. É importante mencionar que o despertar e motivar à leitura se deu após essas aproximações com as demais artes aqui mencionadas, por isso a inversão na forma da leitura das aventuras quixotescas proposta.

Após as pesquisas em equipe cada grupo fez a exposição de seus conhecimentos e leituras para os demais em sala de aula por meio de apresentações no formato de seminários. Um ponto que merece destaque é aquele que ocorreu após a realização das pesquisas, quando os alunos realizaram outros trabalhos como: mural varal, mural imagético, Hqs, dramatização do capítulo dos moinhos de vento, pinturas em quadros, entre outros.

Como foi observado, o diferente deste trabalho traz uma forma distinta de aproximação às obras literárias, dado que as recepções não seguiram os métodos tradicionais de leitura conhecidos na escola. Optou-se por inverter a maneira de ler o clássico deixando para os alunos as buscas pelo conhecimento sobre a obra cervantina e a importância dela para o mundo ficcional e social. Assim, as ações se iniciaram por releituras em diversas formas artísticas proporcionando um despertar, por meio das leituras multimodais que se fazem presentes na contemporaneidade, do interesse para ler o clássico de Cervantes. Sobre isso, Rojo e Barbosa (2015) asseveram que "os textos e gêneros estão cada vez mais multimodais e multi ou hipermidiáticos". Fato que aproxima as leituras do mundo dos discentes o digital, ao mundo ficcional.

De maneira que se finalizaram os trabalhos/leituras por meio de uma exposição nos corredores próximos da sala dos alunos, possibilitando à comunidade escolar conhecer Quixote e Sancho através dos diversos olhares dos discentes. Nesse contexto, pôde-se contemplar as fases do atendimento ao horizonte de expectativa, quanto ao romper com ele, visto que a atividade contemplou outras áreas do conhecimento, o que se fez muito importante, já que o processo de leitura literária tem como pressuposto conduzir o leitor para uma experiência estética, reflexiva e crítica, de forma a romper com o horizonte de expectativa do sujeito leitor que, na sequência básica, denomina-se de interpretação leitora. Para tanto, é relevante pontuar o pensamento de Moran (2015, p.32) quando ele argumenta que "aprender é um processo ativo e progressivo". Segundo o estudioso "o desafio da escola é capacitar o aluno a dar sentido às coisas, compreendê-las e contextualizá-las em uma visão mais integradora, ampla, ligada à sua vida". Tais perspectivas são aplicadas neste trabalho visto que os discentes puderam conhecer a importância da obra de Cervantes contextualizadas à outras significações e de forma compartilhada expuseram e discutiram seus saberes adquiridos por meio de pesquisas nas aulas de língua espanhola. 


\section{As recepções dos leitores do segundo ano do IFPI à Obra Dom Quixote de la Mancha.}

Entende-se que a pedagogia da leitura é um aspecto importante no processo educacional, uma vez que a leitura literária pode proporcionar ao leitor percepções para além de suas construções sociais. Diante dessa perspectiva, e tendo como ponto fundamental o aluno, que está em um processo de formação humana, o ato de ler textos literários torna-se fulcral para o processo de humanização consciente e crítica do ser humano.

Nesse sentido, a percepção de Candido (2004, p. 174) é relevante no que concerne à Literatura. Para ele, "não há povo e não há homem que possa viver sem ela". Segundo o crítico, o texto literário desenvolve em nós a quota da humanidade na medida em que nos torna mais compreensivos e abertos para a natureza, a sociedade, o semelhante. Logo, para que a Literatura se faça um direito presente no ambiente escolar, é necessário dialogar com Cosson (2014), citado por Egito, Alves e Oliveira (2015), quando ele menciona que "é necessário que haja um momento de motivação nas aulas de literatura, uma atividade que traga despertamento ao aluno para o texto literário em vez de simplesmente lançá-la ao aluno". Fato importante visto que a leitura literária do aluno, em geral, fica restrita a fragmentos nos livros ou menções à biografia de escritores que são importantes, porém devese ir além disso.

Quanto à Literatura de língua espanhola, identificou-se que a maioria não havia lido nenhuma obra dessa Literatura, dentre eles, dois mencionaram ter conhecimento da existência obra de Cervantes, porém não haviam lido, e um fez a leitura da obra Casa dos Espíritos, de Isabel Allende. Com isso, verificou-se que a obra Dom Quixote de la Mancha, mesmo sendo um clássico da literatura espanhola, ainda está distante do horizonte leitor de muitos jovens na contemporaneidade.

Assim, verificou-se que o pensamento de Candido (2004), sobre o direito à literatura, merece muita ênfase diante dessas práticas de letramento literário, posto que ainda se identificam estudantes em nível médio com deficiente aproximação ao campo das leituras literárias espanholas. Fato instigante, pois essa língua ainda faz parte do currículo dos alunos do ensino médio nas escolas brasileiras, de forma obrigatória ou opcional, logo há a possibilidade de execução do direito dos alunos à Literatura em suas diversas línguas.

Um outro ponto que merece destaque nessa análise foram as observações das atividades literárias realizadas em sala de aula por meio de apresentações de seminários. Nelas percebeu-se um envolvimento entre os alunos, no sentido de mostrar aos colegas o que fora investigado por eles, como também uma organização sequencial para a exposição das percepções sobre o objeto estudado. $O$ que 
demonstra que as habilidades socioemocionais foram bem desenvolvidas ao longo do trabalho, posto que toda a proposta foi planejada para ser executada em equipes, possibilitando o desenvolvimento da capacidade de lidar com o outro.

Relativamente às questões abertas do formulário, identificou-se que as releituras quixotescas despertaram a sensibilidade do olhar artístico dos discentes. Alguns mencionaram que as diversas ressignificações artísticas da obra demonstraram para eles a importância dela na Literatura, outros relataram as diversas possibilidades que as pessoas têm para conhecer Dom Quixote. Um ponto bem enfatizado pelos alunos, nas releituras quixotescas foi elas terem despertado a imaginação do leitor e proporcionado o prazer de ler. Dentre as várias respostas pontuadas por eles, a ênfase é dada a uma que de certa forma sintetiza o objetivo da atividade, "eu não estava ciente da importância da obra em tantos campos do conhecimento e do lazer".

Diante das observações e dos relatos acima, vários pontos chamam a atenção quanto à recepção da obra por meio dos letramentos, dentre eles, o efeito estético despertado nos receptores da obra, principalmente quanto à imaginação, criatividade e valor, sentimentos muito subjetivos e necessários no letramento literário. Enfim, a relevância do trabalho se dá pelo viés do rompimento do horizonte de expectativa proposto pelo método recepcional no ato de ler textos literários, coadunandose assim à perspectiva da sequência básica relativa à interpretação do leitor nos diversos textos investigados, lidos e compartilhados com seus pares em sala de aula. Visto com isso a possibilidade de uma leitura significativa de Quixote, embora ela tenha sido feita de forma invertida ou diversificada dos modos tradicionais.

\section{Considerações Finais}

Por ser a sala de aula um local que proporciona acontecimentos diversos e muitas vezes específicos por conta da heterogeneidade dos alunos e suas várias realidades de mundo, é sabido que as orientações dos livros, como bem pontuadas orientações, podem e devem ser ressignificadas às realidades dos estudantes, da escola e do planejamento do/a professor/a de língua espanhola para que esse/a desenvolva suas práticas de ensino de forma significativa para os alunos.

Nesse caso específico, a orientação do livro didático serviu como ponto de partida para identificar os horizontes de expectativas dos alunos relativos à leitura literária do clássico Dom Quixote de la Mancha, de Cervantes, para, em seguida proporcionar um rompimento desses horizontes e proporcionar o letramento literário. Como foi visto, as estratégias não seguiram a tradicional leitura da 
obra pela obra, seja ela impressa, seja digital, mas traçaram outras linhas compreendidas como ressignificações artísticas e pesquisas científicas sobre a obra e o personagem quixotesco, isto é, uma possibilidade de se fazer um letramento literário invertido.

Relativamente à estratégia inicial, na leitura do fragmento presente no livro didático, destacase a percepção dos alunos com relação à ação do personagem, Dom Quixote, na cena dos moinhos de vento, fato que reforça a relevância dos clássicos literários no que tange às temáticas emocionais vivenciadas pelo ser humano e que são contempladas nas obras literárias, pois, nessa breve leitura os estudantes expressaram que o personagem era louco, utópico e desequilibrado, entre outros adjetivos.

Além disso, um dado importante foi o interesse despertado para a leitura da obra completa, identificado pela busca da narrativa pelos alunos na biblioteca da escola, ou mesmo, pela compra do livro adaptado, fatos que reforçam a importância desses letramentos no ambiente da sala de aula quando se trabalha com línguas e especialmente o componente curricular língua espanhola, que foi 0 mote deste relato de experiência.

Enfim, identificou-se que o livro didático trouxe a possibilidade para o professor trabalhar a obra literária espanhola em sala de aula, mas isso só é possível quando o/a professor/a não se limita às atividades didáticas sugeridas nele. É importante propor aos alunos, desafios para que se consiga com isso o romper dos horizontes de expectativas do leitor e assim proporcionar o conhecimento das diversas expressões literárias. Verificou-se que essas estratégias foram significativas quanto à aproximação dos alunos ao texto clássico da literatura espanhola - Dom Quixote de la Mancha - visto que a literatura é essencial no processo de construção do conhecimento e humanização do ser humano, assim como na fruição dos receptores percebida nas diversas artes que trazem o personagem quixotesco e suas aventuras.

Pelo exposto foi possível verificar que o espaço da sala de aula é um ambiente adequado para proporcionar aos alunos leituras sobre as diversas obras literárias espanholas de forma prazerosa e significativa. O que é necessário é o uso de estratégias, tanto no que se refere ao uso do livro didático e suas aplicabilidades, quanto na competência para transpassar as orientações das atividades pedagógicas trazidas pelo livro no sentido de obter outros olhares, outras experiências. Com isso, observou-se que, nas aulas de língua espanhola, voltadas para a Literatura, é necessária a formação e a sensibilidade docente para desenvolver habilidades leitoras significativas com os estudantes no espaço da sala de aula.

\section{Referências}

ALBALADEJO, M. Cómo llevar la literatura al aula de ELE: de la teoria a la práctica. MarcoEle Revista de didáctica. ELE, España, 2007. ISSN 1885-2211. 
BARTHES, R. O prazer do texto. Tradução de J. Guinsburg. São Paulo: Perspectiva, 1987.

MORAN, J. Educação híbrida. In: Ensino Híbrido. Organização de: Lilian Bacich;Adolfo Tanzi neto; Frenando Trevisan. Porto Alegre: Penso, 2015.

BONNICl; T; ZOLIN, L. Teoria Literária:abordagens historiográficas e tendências contemporâneas. 2.ed. Maringá: Eduem, 2005.

CALVINO, I. Por que ler os clássicos. Tradução Nilson Molin. São Paulo: Companhia das letras, 1993. Disponível em: letrasclassicas.com.br/../02/Calvino-1993-Por-que-ler-os-classico.arquivo pdf. Acesso em: 23.jul.2020.

CANDIDO, A. Vários escritos. In: O direito a literatura, 4. ed. São Paulo: Rio de Janeiro: duas cidades: Ouro sobre azul, 2004, p.169-191.

COIMBRA, L. Cercanía joven: espanhol, 2º.ensino médio, 2.ed. São Paulo: Edições SM, 2016.

COSSON, R. Círculo de leitura e letramento literário. São Paulo: Contexto, 2019.

COSSON, R. Letramento literário, teoria e prática. 2. ed. São Paulo: Contexto, 2012.

EGITO, G; ALVES, N; OLIVEIRA, T. Literatura em sala de aula: relato de experiência sobre a prática docente, $\quad V$ ENID - UEPB, v. 1, 2015, ISSN 2318-73792015. Disponível: http://www.editorarealize.com.br/revistas/eniduepb/anais.php. Acesso: 21. set. 2019

FONTANA, M. Quebrando paradigmas na leitura técnica: a literatura integrada ao currículo do Instituto Federal de Educação, Ciência e Tecnologia - Campus Sertão/RS. LínguaTec, Bento Gonçalves,n.1,jun.2020.Disponível:

https://periodicos.ifrs.edu.br/index.php/LinguaTec/article/view/3916. Acesso em: 07.set. 2020.

LAJOLO, M. Literatura: leitores e leitura. São Paulo: Moderna, 2001.

PEREIRA, M; SOUZA, L; KIRCHOF,E. Literatura infantojuvenil. Curitiba: Intersaberes, 2013.

ROJO, R; BARBOSA,J. Hipermodernidade, multliletramentos e gêneros discursivos. São Paulo: Parábola, 2015.

SILVA, M; ARAÚJO, R. A estética da recepção e sua aplicabilidade pelo método Recepcional: uma apresentação de Machado de Assis, Revista Fronteira Z, São Paulo, n.14, jul, 2015. Disponível em : https://revistas.pucsp.br/fronteiraz/article/view/22431. Acesso em: 07.set.202.

SILVA, M; PEREIRA, C. A inserção do texto literário em aula de e/le. Revista ensino interdisciplinar RECEl, v.3, 2017. Disponível em: www. periodicos.uern.br > index.php > RECEl > article > download. Acesso em: 18.jan. 2020.

SOARES, K.; MARTINS,T. O objeto e lugar hibrido: uma releitura de Dom Quixote na arte. Cadernos de Comunicação. v. 15, n. 2, Jul/Dez, 2011. Disponível em: https://periodicos.ufsm.br/ccomunicacao/article/view/4721. Acesso: 21.set.2019.

SOUZA, L; . Metodologia do ensino da literatura infanto-juvenil. In: literatura infanto-juvenil. Edgar Kirchof; Luana Sousa; Maria Pereira (Org). Curitiba: Intersaberes, 2013. 
ZILBERMAN, R. O papel da literatura na escola. Via atlântica. São Paulo, 2009. Disponível em: http://www.revistas.usp.br/viaatlantica/article/view/50376. Acesso. 14.jul.2020.

Data de submissão: 28/08/2020. Data de aprovação: 26/10/2020. 